\title{
Zeven jaar klinisch lijnonderwijs aan de Vrije Universiteit: de problemen, de docententraining en het onderwijsmateriaal
}

\author{
J.F. Bastiaans, F.J. van Ittersum, S. Huinink, M.H. Sagasser, A.J. Gercama, M. de Haan
}

\begin{abstract}
Samenvatting
De Faculteit Geneeskunde van de Vrije Universiteit kent sinds 1990 het klinisch lijnonderwijs $(K L O)$. Hierin wordt op probleemgestuurde wijze klinisch redeneren geoefend met behulp van casuïstiek. Onlangs is het KLO geëvalueerd en is aan de hand van de gesignaleerde problemen een docententraining georganiseerd met als belangrijkste doel het oefenen in het schrijven van onderwijsmateriaal (casuïstiek) voor het KLO. Na deze training zijn docenten zelf het onderwijsmateriaal gaan (her)schrijven met begeleiding van een projectgroep. Inmiddels zijn de meeste casus voor het KLO aangepast en is er een permanente redactiecommissie KLO ingesteld, die de kwaliteit van het onderwijsmateriaal bewaakt. In dit artikel wordt de docententraining beschreven, evenals de uitkomsten daarvan met betrekking tot het vernieuwde onderwijsmateriaal. (Bastiaans JF, Ittersum FJ van, Huinink S, Sagasser MH, Gercama AJ, Haan M de. Zeven jaar klinisch lijnonderwijs aan de Vrije Universiteit: de problemen, de docententraining en het onderwijsmateriaal. Tijdschrift voor Medisch Onderwijs 2000;19(5): 218-224.)
\end{abstract}

\section{Inleiding}

Sinds 1990 kent het curriculum van de faculteit geneeskunde van de Vrije Universiteit Amsterdam (VU) het klinisch lijnonderwijs (KLO). Dit onderwijs is aanvankelijk samen met de Universiteit van Amsterdam (UvA) ontwikkeld en beoogt het aanleren van medisch probleemoplossen aan de hand van patiëntencasuïstiek. ${ }^{12}$ Het KLO loopt in het curriculum parallel aan het blokonderwijs, dat gericht is op kennisverwerving. In het KLO zijn grootschalig en kleinschalig onderwijs aan elkaar gekoppeld. Grootschalig zijn de demonstratiecolleges met patiënten; kleinschalig zijn de voorbereiding en feedback op de patiëntendemonstraties aan de hand van casuïstiek in probleemgestuurde onderwijsgroepen van ongeveer vijftien studenten. In het tweede studiejaar ligt de nadruk op anamnese, lichamelijk onderzoek en hypothesevorming, in het derde studiejaar op aanvullend onderzoek, en in het vierde studiejaar op medisch beleid (de 'jaarthema's KLO'). Een centrale commissie is verantwoordelijk voor inhoud, uitvoering en toetsing.

In 1995 werd in het Evaluatierapport Klinisch Lijnonderwijs geconcludeerd dat enkele inhoudelijke doelstellingen niet gehaald werden. ${ }^{3} \mathrm{Om}$ het KLO te verbeteren, werd in de periode van september 1997 tot september 1998 een project uitgevoerd. In dit artikel worden de uitvoering en de uitkomsten van dit project beschreven.

\section{Doelstellingen en werkwijze van het project}

Naar aanleiding van de beschikbare evaluatiegegevens van het KLO werden de volgende doelstellingen voor het project bepaald:

1. actualiseren van de KLO-onderwerpen in overeenstemming met de eindtermen van het Raamplan 1994 artsopleiding; 
2. verbetering van de casuïstiek, zodat er duidelijke aanknopingspunten zijn voor het oefenen in medisch probleemoplossen;

3. verbetering van de begeleiding van de onderwijsgroepen door instructie van tutoren en aanpassing van de tutorhandleidingen met expliciete aandacht voor medisch probleemoplossen. ${ }^{4}$

Er werd een projectgroep ingesteld bestaande uit een internist, een huisarts, een psychiater (in opleiding) en een (medisch) onderwijskundige. Elke twee maanden rapporteerde deze projectgroep haar bevindingen en legde zij plannen ter fiattering voor aan de centrale KLO-commissie.

Begonnen werd met een grondige bestudering van de literatuur over onderwijs in klinisch redeneren. Twee leden uit de projectgroep volgden de module 'Onderwijs in klinisch redeneren' van de stichting Onderwijskundige en Didactische Ontwikkeling en Scholing (ODOS). Vervolgens werd een vergelijking gemaakt met het Raamplan 1994 artsopleiding. ${ }^{5}$ Daarbij werd gekeken in hoeverre de medische aspecten van de algemene eindtermen uit het Raamplan (hoofdstuk 7) en de lijst van medische problemen (hoofdstuk 8) in het KLO aan bod kwamen. Ter oriëntatie werden bezoeken gebracht aan zusterfaculteiten met een specifieke onderwijslijn klinisch redeneren (Groningen, Nijmegen, Amsterdam (UvA)) en werden aldaar onderwijsmethodiek en -inhoud besproken. Daarna volgde een meer gedetailleerde analyse van het KLO door het beoordelen van de inhoud van de werkboeken KLO, het bijwonen van colleges KLO (patiëntendemonstraties) en aan de hand van facultaire evaluaties van het functioneren van de onderwijsgroepen. Jaarvertegenwoordigers van de studenten leverden eigen evaluaties aan de projectgroep. Tenslotte werd de programmering van het KLO in relatie met het blokonderwijs tegen het licht gehouden en werd gekeken of de jaarthema's KLO in de verschillende studiejaren voldoende herkenbaar aan bod kwamen.

\section{Analyse van de problemen}

Uit de analyse kwam een aantal zaken naar voren. Er was een aantal doublures in het KLO. Bijna alle medische patiëntenproblemen die in het KLO aan bod kwamen, waren terug te vinden in de lijst van medische problemen in het Raamplan 1994. Omgekeerd bleek dat ongeveer 30\% van de problemen uit het Raamplan niet aan bod kwam in het KLO. Een aantal onderwerpen bleek uit het KLO verdwenen te zijn, ondanks in het verleden gemaakte afspraken. Doordat het KLO niet aangepast was aan de verschuiving van een aantal blokken in de periode 1990-1997, klopte de aansluiting van het KLO aan sommige blokken niet meer. De participatie van studenten aan het KLO was niet optimaal. Studenten bereidden zich onvoldoende gericht voor op de onderwijsgroepen. Ten grondslag daaraan lagen vaak ontbrekende of te onduidelijke leerdoelen bij het onderwijsmateriaal, onduidelijke literatuurverwijzingen en/of een te weinig uitdagende casus, waardoor het klinisch redeneren onvoldoende gestimuleerd werd. Bovendien werd een deel van de casus te kort van tevoren aan de studenten gegeven. Een algemeen knelpunt was dat het voor veel docenten niet eenvoudig was om onderscheid te maken tussen het doceren van (biomedische) blokkennis en het doceren van medisch probleemoplossen. Dientengevolge waren de casuïstiek en bijbehorende colleges KLO niet altijd gericht op het expliciteren van dit probleemoplossen. Tenslotte kwam naar voren dat de aansluiting tussen het werken met casus in probleemgestuurde onderwijsgroepen en de colle- 
ges KLO met demonstratiepatiënten niet altijd even goed uit de verf kwam. In de onderwijsgroepen werd te weinig teruggekoppeld naar de colleges en andersom werd in de colleges niet altijd expliciet teruggekomen op de in de groepen behandelde patiëntenproblemen.

\section{Oplossingen}

Naar aanleiding van de analyse van de problemen heeft de projectgroep in het studiejaar 1997-1998 een training georganiseerd voor de KLO-docenten. Deze training had als doel de docenten opnieuw te informeren over doelstellingen, inhoud en methodiek van het KLO, hen bewust te maken van de knelpunten en hen onderwijskundig bij te scholen. Mede door deze training werd de onderlinge communicatie tussen KLO-docenten bevorderd. De docententraining was vooral bedoeld als voorbereiding op een kwaliteitsverbetering van het door de docenten te maken onderwijsmateriaal. De projectgroep heeft een aantal criteria opgesteld waaraan de casuïstiek voor het KLO moet voldoen:

- aanwezigheid en/of relevantie van leerdoelstellingen;

- aansluiting bij de reeds gedoceerde (blok)kennis;

- aansluiting bij het thema van het betreffende KLO studiejaar;

- aanwezigheid en/of relevantie van literatuurverwijzingen;

- aansluiting van de vragen bij de casus;

- lokken casus en vragen medisch probleemoplossen uit?

- aanwezigheid van een handleiding voor peergroepbegeleiders met uitgewerkte 'benaderingsstrategie' voor het medisch probleemoplossen;

- in geval van gebruik van aanvullende diagnostiek verwijzing naar het Diagnostisch kompas. ${ }^{6}$

\section{De docententraining}

De training, die één dag besloeg, werd tweemaal aangeboden. In totaal hebben 26 van de 36 docenten (72\%) de training gevolgd. Een belangrijk doel van de training was om de docenten te laten oefenen met het ontwikkelen van onderwijsmateriaal. Belangrijk hierbij is dat docenten zich bewust worden van verschillen in kennis en vaardigheid in het probleemoplossen tussen beginners en experts. Hier werd in de training aandacht aan besteed. ${ }^{8}$ De kennis van experts en beginners verschilt in omvang, aard en in de wijze waarop de kennis georganiseerd is. Dit wordt deels veroorzaakt door verschillen in ervaring. Het is goed denkbaar dat een expert een casus ontwerpt, die niet goed aansluit bij het niveau van een beginner, waardoor de kans bestaat dat de beoogde effecten niet worden bereikt. Voor experts kan het moeilijk zijn in te schatten hoe een casus door beginners wordt ervaren. In de training werden de docenten daarom eerst in de rol van een relatieve beginner geplaatst door hun een niet-medische casus aan te bieden. $\mathrm{Na}$ deze ervaring met probleemoplossen als beginner, werd pas geoefend in het ontwikkelen van een casus voor medisch probleemoplossen.

De docenten werden verdeeld in groepjes van vier of vijf docenten uit verschillende disciplines. Bij de eerste oefening kreeg men de opdracht om als groep een geschikte brander uit te zoeken voor een te ondernemen vakantiereis. Twee varianten (figuur 1) werden aangeboden: in variant 1 (de 'vette' casus) werden meer gegevens aangeboden dan in variant 2 (de 'magere' casus). Bij beide varianten moest nagegaan worden welke factoren van belang zijn bij de keuze van een brander en welke voor deze keuze noodzakelijke gegevens nog ontbraken. Vervolgens moest op grond van de beschikbare gegevens 
een gemotiveerde keuze voor een brander gemaakt worden. De veronderstelling was dat de deelnemende docenten bij de twee varianten verschillende keuzes en situaties zouden ervaren.

Bij de eerste keer dat de training gegeven werd, bleek de 'magere' groep informatieachterstand te ervaren. Men meende de opdracht daardoor niet goed uit te kunnen voeren. Resultaat was dat men zich met andere dingen dan de opdracht bezig hield. Deze situatie herhaalde zich niet bij de tweede training. Bij deze training maakten de 'magere' groepen veel aannames en voerden op basis daarvan de opdracht uit. Op zich is dit een goede aanpak, al is het niet altijd inzichtelijk of aannemelijk dat de juiste aannames worden gemaakt. De 'vette' groep kon zich meer met de feitelijke discussie bezig houden, omdat door de verstrekte informatie minder aannames nodig waren. Bij beide trainingen hebben de deelnemende docenten door deze oefening ervaren dat het belangrijk is dat onderwijsmateriaal helder is en aansluit bij leerdoelen, opdat de beoogde effecten bereikt kunnen worden.

Oefening 2 was gericht op het ontwikkelen van een casus voor het medisch probleemoplossen. Hierbij lagen de algemene doelen en het thema (moeheid) vast. Er moesten een casus voor tweedejaars en een casus voor vierdejaars studenten gemaakt worden (figuur 2). De opdracht werd in vier stappen uitgevoerd. Eerst moest het thema gespecificeerd worden (moeheid op basis van...). Vervolgens moesten specifieke leerdoelen (binnen het thema en passend bij het niveau van het studiejaar) geschreven worden. Als derde stap werd benoemd met welke (combinatie van) strategieën het medisch probleem benaderd kon worden. Strategieën kunnen bijvoorbeeld anatomisch, pathofysiologisch, psychopathologisch en/of epidemiologisch/besliskundig van aard zijn.

Figuur 1. Eerste oefening docentencursus.

\section{De vette casusvariant}

$U$ gaat met 6 mensen in de maand oktober een trektocht maken in het Himalayagebergte op een hoogte van 4000 meter. $U$ reist per vliegtuig naar Tibet. In de Himalaya trekt $u$ onder begeleiding van een gids met 4 sherpa's. Als budget voor de reis is voor de groep in totaal $f 16.000$ beschrikbaar. $U$ heeft als taak een geschikte brander uit te zoeken om te koken.

\section{De 'magere' casusvariant}

$U$ gaat met 6 mensen in de maand november 4 weken kamperen in Zimbabwe. Ter voorbereiding op de reis wilt $u$ een geschikte brander uitzoeken om te koken.

\section{Vragen voor beide varianten}

- Welke factoren zijn van belang bij de keuze van een brander?

- Welke gegevens ontbreken nog?

- Maak op grond van de beschikbare gegevens een keuze voor een brander. Motiveer uw antwoord.

De docenten kregen een drietal 'publicaties' over verschillende gasbranders aangeboden. Deze konden bij de besluitvorming gebruikt worden. 
Figuur 2. Tweede oefening docentencursus.

Schrijf voor tweedejaarsstudenten en voor vierdejaarsstudenten geneeskunde een casus met vragen over het onderwerp 'moeheid'. Voordat u de twee casus maakt, moet u eerst het kader bepalen, waarbinnen deze casus zich afspelen.

Stel hiertoe eerst met elkaar voor beide casus de volgende punten vast.

1. Kies een ziektebeeld (zie bijlage).

2. Specificeer de leerdoelen.

3. Kies een benaderingstrategie (zie bijlage over strategieën).

De docenten kregen een ziektebeeldenlijst en een bijlage over benaderingsstrategieën in klinisch redeneren. Deze konden bij de besluitvorming gebruikt worden.

Door deze strategieën bij het ontwerpen van de casus te benoemen, kunnen ze bewust in de casus en de vragen ingebouwd worden. Tot slot werd de casus geschreven en werden bijbehorende vragen geformuleerd.

Deze oefening vond men ogenschijnlijk eenvoudig, maar bij de nabespreking bleken er valkuilen te zijn. De geformuleerde specifieke leerdoelen waren soms erg ruim en/of globaal. Sommige casus veronderstelden voorkennis van studenten, die in het betreffende studiejaar nog niet aanwezig kon zijn. Niet altijd werd benoemd wat de veronderstelde voorkennis was. Enkele casus bleken niet meer aan te sluiten bij de eerder geformuleerde uitgangspunten. Vaak ontbrak de vraag aan studenten om hun keuze te beargumenteren, terwijl daarmee juist het denkproces zichtbaar wordt. Af en toe werd de casus gebruikt om theorie uit te leggen in plaats van studenten deze te laten toepassen. Sommige casus vielen op door hun gedegen opbouw, waarbij het door de studenten te volgen traject goed werd aangegeven.

$\mathrm{Na}$ afloop werd de training geëvalueerd met behulp van schriftelijke open vragen. Men gaf aan geleerd te hebben dat de vorm van de casus van belang is. Ook het belang van de aansluiting van de leerdoe- len op de casusvragen werd genoemd. Verder gaf men aan dat er verschil is tussen tweede-, derde- en vierdejaars studenten en dat deze qua inhoud andere casus vereisen. De docenten gaven aan dat het moeilijker was om een casus te ontwikkelen voor tweedejaars studenten dan voor vierdejaars, omdat het inschatten van het niveau van tweedejaars studenten moeilijker is, terwijl vierdejaars studenten al zo veel weten dat vrijwel alles in een casus kan worden opgenomen. Doordat er ervaringen tussen de docenten werden uitgewisseld, heeft men meer inzicht gekregen in het KLO. De opbouw van de training vond men goed, evenals het feit dat er veel zelfwerkzaamheid in kleine groepen was. De samenwerking tussen diverse disciplines was leerzaam en de informele sfeer werd zeer gewaardeerd. Het feit dat op deze manier aandacht werd besteed aan onderwijs werkte enthousiasmerend. De training kon echter niet in alle vragen van docenten voorzien. Onder andere werd de behoefte geuit aan concrete definities van 'medisch probleemoplossen' of 'de methode om een casus te schrijven'. Er is gevraagd om een handleiding ter toelichting op het stappenplan waarmee in de training gewerkt is. De projectgroep heeft inmiddels voorzien in deze handleiding. ${ }^{9}$ 


\section{Verbetering van het onderwijsmateriaal}

Naar aanleiding van de analyse van de problemen binnen het KLO werd een aantal maatregelen getroffen om de uniformiteit en kwaliteit van het onderwijs te verbeteren. Besloten werd alle casuïstiek die in het onderwijs gebruikt werd, in de KLO-syllabi op te nemen. De klinisch docent kan zelf bepalen wanneer een bepaald onderwerp behandeld wordt, zodat hij de gelegenheid heeft een geschikte patiënt te zoeken voor het college. Voorwaarde is echter wel dat de docent ruim van tevoren aan de studenten bekend maakt welke casus hij bespreekt, zodat zij de gelegenheid hebben de casus (uit de syllabus) voor te bereiden.

De patiëntencasuïstiek uit het studiejaar 1996-97 is als uitgangspunt genomen voor de evaluatie door de projectgroep. Met behulp van de eerder genoemde beoordelingscriteria is feedback gegeven op de casus aan de betreffende auteur-docenten. Gevraagd werd de casuïstiek te herschrijven. Hierbij konden de docenten gebruik maken van de docentenhandleiding met adviezen en richtlijnen voor het schrijven van een casus, die door de projectgroep gemaakt was naar aanleiding van de docententraining. Het herschrijven van de casus kon tot de volgende acties leiden: het kiezen van een nieuw onderwerp omdat de casus niet aansloot bij de bestaande stof; het overnemen van een be- staande casus (met enkele kleine correcties); of het herschrijven van een casus zonder dat het onderwerp werd aangepast.

Bij de aanpassing van de casuïstiek (in totaal 49 casus over alle doctoraaljaren) viel op dat het merendeel van de casus volledig werd herschreven $(65 \%)$; slechts een klein deel van de casus onderging een kleine aanpassing (19\%) of veranderde van onderwerp (16\%) (tabel 1). ${ }^{10}$ Door de training zijn de problemen bij het ontwikkelen van onderwijsmateriaal duidelijk gemaakt en is de communicatie tussen docenten bevorderd. Voor het onderwijs in zijn algemeenheid zou het goed zijn wanneer op gezette tijden dergelijke (thema)bijeenkomsten zouden plaatsvinden.

\section{Tot slot}

Na de feedback op het door henzelf geschreven onderwijsmateriaal waren de meeste docenten zich bewust van de knelpunten en hebben zij hard gewerkt om de casuïstiek bij te stellen. Alle casus in alle KLO-jaren zijn uiteindelijk aangepast of herschreven en in de syllabi opgenomen. De casus zijn voorzien van leerdoelen en literatuurverwijzingen; de kenmerken per jaar zijn duidelijk zichtbaar en de nadruk ligt nu veel meer dan in het verleden op het toepassen van kennis bij het medisch probleemoplossen.

Tabel 1. Overzicht aanpassing casuïstiek KLO in de doctoraaljaren 1, 2 en 3.

\begin{tabular}{lllll}
\hline Doctoraaljaar & $\begin{array}{l}\text { Aantal beschikbare } \\
\text { casus }\end{array}$ & $\begin{array}{l}\text { Nieuw onderwerp } \\
\text { vastgesteld }\end{array}$ & $\begin{array}{l}\text { Kleine aanpassing } \\
\text { gemaakt }\end{array}$ & $\begin{array}{l}\text { Nieuwe casus } \\
\text { gemaakt }\end{array}$ \\
\hline 1 & 13 & 1 & 4 & 8 \\
2 & 15 & 3 & 3 & 9 \\
3 & 21 & 4 & 2 & 15 \\
Totaal & $49(100 \%)$ & $8(16 \%)$ & $9(19 \%)$ & $32(65 \%)$ \\
\hline
\end{tabular}


Inmiddels is er per september 1998 vernieuwd en verbeterd onderwijsmateriaal ter beschikking gekomen. Omdat uit de analyse van de problemen gebleken was dat een strakkere centrale aansturing noodzakelijk was, is met ingang van het studiejaar 1998-1999 een permanente redactiecommissie KLO ingesteld ter bewaking van de kwaliteit van het onderwijs.

\section{Literatuur}

1. Cate ThJ ten, Schadé E. Workshops klinische besluitvorming. Een jaar ervaring met kleinschalig theoretisch klinisch lijnonderwijs. In: Metz JCM, Scherpbier AJJA, Houtkoop E, redactie. Gezond Onderwijs 2. Nijmegen: Universitair Publikatiebureau; 1993. p. 215-22.

2. Cate ThJ ten. Kleinschalig theoretisch klinisch lijnonderwijs. Ned Tijdschr Geneeskd 1994;138 (24):1238-43.

3. Lambert J. Evaluatierapport klinisch lijnonderwijs Faculteit Geneeskunde. Amsterdam: Vrije Universiteit; 1995.

4. Bastiaans JF, Huinink S, Ittersum FJ van, Sagasser MH. Rapport OKF-project: klinisch probleemoplossen in de praktijk. Amsterdam: Vrije Universiteit; 1998.

5. Metz JCM, Pels Rijcken-Van Erp Taalman Kip EH, Brand-Valkenburg BWM van den. Raamplan 1994 artsopleiding. Eindtermen van de artsopleiding. Nijmegen: Universitair Publikatiebureau Katholieke Universiteit Nijmegen; 1994.

6. Diagnostisch kompas: voorlichting over aanvullende diagnostiek. Amstelveen: Ziekenfondsraad; 1997.

7. Boshuizen HPA, Schmidt HG. Kennisontwikkeling en onderwijs in de geneeskunde: een subtiel evenwicht. Bulletin Medisch Onderwijs 1993;12:98-109.

8. Boshuizen HPA, Schmidt HG. De ontwikkeling van medische expertise; implicaties voor praktisch en theoretisch medisch onderwijs. In: Metz JCM, Scherpbier AJJA, Vleuten CPM van der, redactie. Medisch onderwijs in de praktijk. Assen: Van Gorcum; 1995. p. 24-39.
9. Sagasser MH, Gercama AJ, Ittersum FJ van, Huinink S, Bastiaans JF, Haan M de. Zeven jaar klinisch lijnonderwijs aan de Vrije Universiteit: De docententraining. In: Spaai GWG, Verweij AMJJ, Remmen R, Dolmans DHJM, Denekens JPM, Smal JA, et al., redactie. Gezond Onderwijs - 8. Proceedings Gezond Onderwijs Congres 1998. Houten/Diegem: Bohn Stafleu Van Loghum; 1999. p. 256-9.

10. Huinink S, Sagasser MH, Bastiaans JF, Ittersum FJ van, Haan M de. Zeven jaar klinisch lijnonderwijs aan de Vrije Universiteit: het onderwijsmateriaal. In: Spaai GWG, Verweij AMJJ, Remmen R, Dolmans DHJM, Denekens JPM, Smal JA, et al., redactie. Gezond Onderwijs - 8. Proceedings Gezond Onderwijs Congres 1998. Houten/Diegem: Bohn Stafleu Van Loghum; 1999. p. 180-2.

\section{De auteurs:}

J.F. Bastiaans, huisarts/universitair docent, Afdeling HVSG, Faculteit Geneeskunde der Vrije Universiteit Amsterdam.

F.J. van Ittersum, internist-nefroloog/universitair docent, Afdeling Nefrologie, Academisch Ziekenhuis der Vrije Universiteit Amsterdam.

S. Huinink, psychiater i.o., destijds werkzaam bij de PCD, Academisch Ziekenhuis der Vrije Universiteit Amsterdam.

M.H. Sagasser, onderwijskundige, destijds werkzaam bij het Onderwijsbureau Faculteit Geneeskunde der Vrije Universiteit Amsterdam.

A.J. Gercama, huisarts/universitair docent, Afdeling HVSG, Faculteit Geneeskunde der Vrije Universiteit Amsterdam.

M. de Haan, hoogleraar huisartsgeneeskunde, Afdeling HVSG, Faculteit Geneeskunde der Vrije Universiteit Amsterdam.

\section{Correspondentieadres:}

J.F.Bastiaans, Afdeling HVSG, Faculteit Geneeskunde, Vrije Universiteit, Van der Boechorststraat 7, 1081 BT Amsterdam, e-mail: jf.bastiaans.gpnh@med.vu.nl

\section{Summary}

Since 1990 case-based problem-orientated courses in clinical reasoning have been part of the curriculum of the Faculty of Medicine of the Vrije Universiteit Amsterdam. To tackle problems identified by a recent evaluation of the course, teachers participated in courses where they practised in constructing cases to be used in the clinical reasoning course. Following the courses most of the existing cases in use in the curriculum were adapted or rewritten. A permanent editorial committee has been set up to monitor case construction. In this article the teacher training courses are described as well as the ensuing revision of the clinical cases. (Bastiaans JF, Ittersum FJ van, Huinink S, Sagasser MH, Gercama AJ, Haan $M$ de. Seven years experience with a longitudinal course on clinical reasoning skills: bottlenecks, teacher training, educational resources. Dutch Journal of Medical Education 2000;19(5): 218-224.) 